\title{
Evidence for a Solid-Electrolyte Inductive Effect in Superionic Conductors
}

Sean P. Culver ${ }^{\mathrm{a}, \mathrm{b}, \$}$, Alexander G. Squires ${ }^{\mathrm{c}, \mathrm{d}, \$}$, Nicolò Minafra ${ }^{\mathrm{e}}$, Callum W. F. Armstrong ${ }^{\mathrm{c}}$, Thorben Krauskopf a,b, Felix Böchera ${ }^{\mathrm{a}, \mathrm{b}}$, Cheng Li ${ }^{\mathrm{f}}$, Benjamin J. Morgan*c,d,

Wolfgang G. Zeier*,e

${ }^{a}$ Institute of Physical Chemistry, Justus-Liebig-University Giessen, Heinrich-Buff-Ring 17, D-35392 Giessen, Germany.

${ }^{b}$ Center for Materials Research (LaMa), Justus-Liebig-University Giessen, Heinrich-Buff-Ring 16, D-35392 Giessen, Germany.

${ }^{c}$ Department of Chemistry, University of Bath, Claverton Down, BA2 7AY, United Kingdom.

${ }^{d}$ The Faraday Institution, Didcot, OX11 ORA, United Kingdom.

'Institute of Inorganic and Analytical Chemistry, University of Münster, Correnstrasse 30, 48149 Münster, Germany.

fJülich Centre for Neutron Science JCNS, Forschungszentrum Jülich GmbH, Outstation at SNS,

1 Bethel Valley Road, Oak Ridge, Tennessee 37831-6473, United States.

*b.j.morgan@bath.ac.uk; wzeier@uni-muenster.de

\$These authors contributed equally to the manuscript 


\begin{abstract}
Identifying and optimizing highly-conducting lithium-ion solid electrolytes is a critical step towards the realization of commercial all-solid-state lithium-ion batteries. Strategies to enhance ionic conductivities in solid electrolytes typically focus on the effects of modifying their crystal structures or of tuning mobile-ion stoichiometries. A less-explored approach is to modulate the chemical-bonding interactions within a material to promote fast lithium-ion diffusion. Recently, the idea of a solid-electrolyte inductive effect was proposed, whereby changes in bonding within the solid-electrolyte host-framework modify the potential-energy landscape for the mobile ions, resulting in an enhanced ionic conductivity. This concept has since been invoked to explain anomalous conductivity trends in a number of solid electrolytes. Direct evidence for a solid-electrolyte inductive effect, however, is lacking - in part because of the challenge of quantifying changes in local bonding interactions within a solid-electrolyte host-framework. Here, we consider the evidence for a solid-electrolyte inductive effect in the archetypal superionic lithium-ion conductor $\mathrm{Li}_{10} \mathrm{Ge}_{1-x} \mathrm{Sn}_{x} \mathrm{P}_{2} \mathrm{~S}_{12}$, using Rietveld refinements against highresolution temperature-dependent neutron-diffraction data, Raman spectroscopy, and density functional theory calculations. Substituting Ge for Sn weakens the $\{\mathrm{Ge}, \mathrm{Sn}\}-\mathrm{S}$ bonding interactions and increases the charge-density associated with the $\mathrm{S}^{2-}$ ions. This charge redistribution modifies the $\mathrm{Li}^{+}$substructure causing $\mathrm{Li}^{+}$ions to bind more strongly to the hostframework S anions; which in turn modulates the Li-ion potential-energy surface, increasing local barriers for Li-ion diffusion. Each of these effects is consistent with the predictions of the solid-electrolyte inductive effect model. Density functional theory calculations further predict that this inductive effect occurs even in the absence of changes to the host-framework geometry due to $\mathrm{Ge} \rightarrow \mathrm{Sn}$ substitution. These results provide direct evidence in support of a measurable solid-electrolyte inductive effect and demonstrate its application as a practical strategy for tuning ionic conductivities in superionic lithium-ion conductors.
\end{abstract}




\section{Introduction}

The last decade has seen numerous advances in the development and optimization of ionic conductors for solid-state battery applications, ${ }^{1-3}$ with particular attention directed towards lithium thiophosphates; these include the $\mathrm{Li}_{6} \mathrm{PS}_{5} X$ argyrodites, ${ }^{4-13}$ the thio-LISICON phases, ${ }^{14}$ 18 and $\mathrm{Li}_{10} \mathrm{GeP}_{2} \mathrm{~S}_{12}{ }^{19}$ and its substitutional analogs. ${ }^{20-25}$ Within the $\mathrm{Li}_{10} \mathrm{GeP}_{2} \mathrm{~S}_{12}$ family, roomtemperature ionic conductivities have been reported in excess of $10 \mathrm{mS} \mathrm{cm}{ }^{-1},{ }^{19}$ and similarly high ionic conductivities have been reported for other lithium thiophosphates. ${ }^{11,12,19}$ Understanding the factors that cause specific solid electrolytes to exhibit fast or slow ionictransport is a key research question, in part because such an understanding can inform the development of general "design rules" and support the identification and optimization of new fast-ion conducting materials, ${ }^{26-29}$ thereby broadening the pool of candidate solid electrolytes for future solid-state battery applications. A partial answer to the question of what makes some solid electrolytes much faster ionic conductors than others comes from an understanding of favorable structural motifs - for example, fast-ion conduction is favored in materials that possess highly connected networks of lithium-diffusion pathways. ${ }^{26}$ Families of structurally related solid electrolytes, however, often exhibit room temperature ionic conductivities that vary by several orders of magnitude, highlighting the important role of chemical composition as a factor in understanding ionic conductivity trends between similar solid electrolytes. ${ }^{30}$

The $\mathrm{Li}_{10} M \mathrm{P}_{2} \mathrm{~S}_{12}(M=\mathrm{Si}, \mathrm{Ge}, \mathrm{Sn})$ thiophosphates adopt a tetragonal structure consisting of an anionic host-framework of $\mathrm{MS}_{4}{ }^{4-}$ and $\mathrm{PS}_{4}{ }^{3-}$ tetrahedra that accommodates interstitial lithium ions (Figure 1). This host-framework structure has open channels oriented along the [001] direction (Figure 1a) that enable fast lithium diffusion along $c$, while secondary conduction pathways between these $c$-oriented channels allow slower diffusion in the $a-b$ plane. ${ }^{31}$ The dominant lithium diffusion process along $c$ consists of lithium ions moving through alternating $\operatorname{Li}(1)$ and $\operatorname{Li}(3)$ sites (Figure $1 b),{ }^{31,32}$ where the rate of lithium diffusion depends on the underlying lithium-ion potential-energy-surface. The lithium-ion potential-energy profile is determined both by the electrostatic interactions between lithium ions and by the interactions between the mobile lithium ions and the host-framework. ${ }^{31-34}$ Chemical substitution may affect both the geometry and charge-density-distribution of the host-framework, and both effects can modulate the lithium-ion potential-energy profile, resulting in either increased or decreased lithium-ion conductivity. ${ }^{21,35}$ 


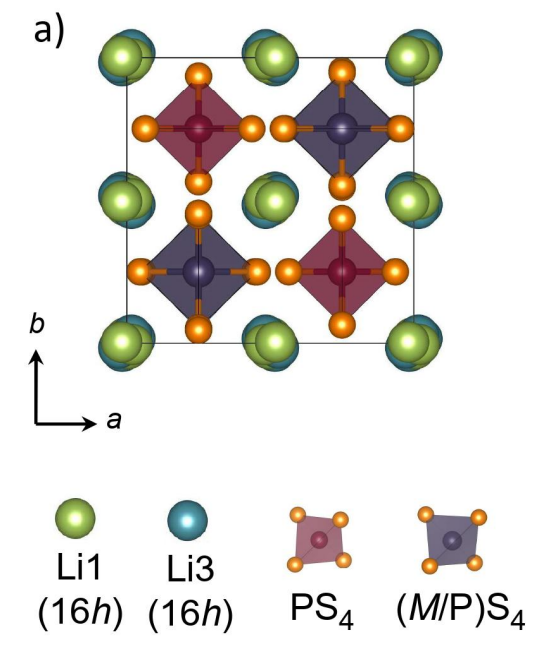

b)

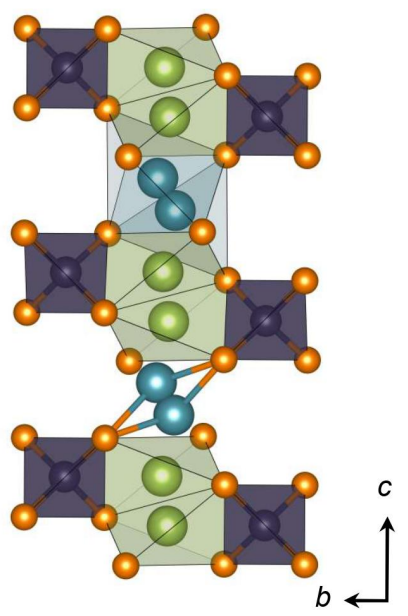

Figure 1: (a) View of the $\mathrm{Li}_{10} M \mathrm{P}_{2} \mathrm{~S}_{12}$ unit cell, oriented along the c-axis, showing the onedimensional primary lithium-diffusion channels. (b) View of the same cell, oriented along the a-axis, showing the sequence of Li(1) and Li(3) lithium sites along the c-oriented diffusion channels, and the positions of the adjacent $(M / P) S_{4}$ tetrahedra.

Chemical substitution within a solid-electrolyte host-framework is a well-established strategy for enhancing the ionic conductivities of specific solid electrolytes. ${ }^{26}$ The selection of potentially beneficial framework-atom substitutions is typically guided by extrapolating from trends observed in other solid-electrolyte families, or by considering geometric models that aim to predict how particular substitutions might affect the structure of the host-framework. One such model, for example, considers the increase in crystal volume that occurs when small framework atoms are replaced with larger substitute species. The resulting expansion of the electrolyte framework is expected to increase the interstitial volume available to diffusing lithium, thereby promoting lithium conduction. ${ }^{36}$ An alternative model considers how substitution of specific framework atoms can affect the local geometry of critical lithium diffusion pathways, in some cases causing an expansion or contraction of "bottlenecks", thereby promoting or impeding lithium diffusion. ${ }^{35}$ Geometric models, such as these, often provide simple intuitive explanations for the conductivity trends observed within families of solid electrolytes. In some notable cases, however, observed conductivity trends run counter to those predicted on geometric grounds; chemical substitutions that would be expected to increase lithium-ion conductivities instead give the opposite effect and decrease ionic conductivities. One example of this contrary behavior is the isovalent substitution of Ge with the larger and more polarizable $\mathrm{Sn}$ within the $\mathrm{Li}_{10}\{\mathrm{Ge}, \mathrm{Sn}\} \mathrm{P}_{2} \mathrm{~S}_{12}$ system, which was initially expected to 
produce an increased ionic conductivity due to an increase in overall lattice volume, but in practice gives the opposite trend, with increasing Sn content giving a decreased lithium-ion conductivity. ${ }^{23,35}$

Krauskopf et al. ${ }^{35}$ have recently suggested that this "inverted" response to chemical substitution might be explained by a solid-electrolyte inductive effect. ${ }^{35}$ This model predicts that the lower electronegativity of $\mathrm{Sn}$ versus Ge causes $\mathrm{Sn}-\mathrm{S}$ bonds to be more polar than equivalent $\mathrm{Ge}-\mathrm{S}$ bonds (see Figure 2), ${ }^{i}$ with Sn-bonded sulfur atoms therefore having an increased associated negative-charge-density than equivalent Ge-bonded sulfur atoms. ${ }^{\text {ii }}$ This increased negative charge for $\mathrm{Sn}$-bonded sulfur atoms compared to Ge-bonded sulfur atoms means that the electrostatic $\mathrm{S} \cdots \mathrm{Li}$ interaction between these sulfur atoms and nearby lithium ions is stronger in the Sn-substituted system than in the Ge-analogue. In LGPS the Li(3) site sits closer to these $\{\mathrm{Ge}, \mathrm{Sn}\}$-bonded $\mathrm{S}$ atoms than the $\mathrm{Li}(1)$ site does; an increased $\mathrm{S} \cdots \mathrm{Li}$ interaction is therefore predicted to stabilize the $\operatorname{Li}(3)$ site compared to the $\operatorname{Li}(1)$ site. This increases the effective potential-energy barrier for lithium diffusion along the $\operatorname{Li}(3)-\operatorname{Li}(1)$ channels and results in a reduced lithium-ion conductivity.

a)

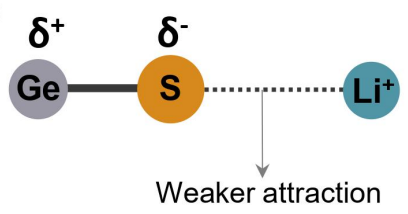

b)

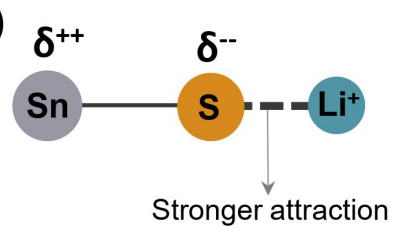

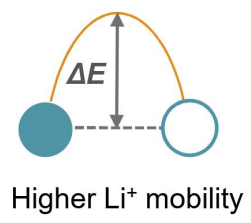

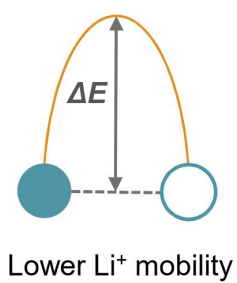

Figure 2: Schematic of the predicted difference in $M-S \cdots L i$ bonding for $M=$ Ge versus $M=S n$, due to a hypothetical inductive effect. Changes in the $M-S$ bonding modulate the

\footnotetext{
i The electronegativities of $\mathrm{Ge}^{4+}$ and $\mathrm{Sn}^{4+}$ are 2.0 versus 1.7 Pauling units on the Allred-Rochow scale of electronegativity with 1 Pauling unit $=6 \mathrm{eV} \cdot \mathrm{e}^{-166}$ and $11.1 \mathrm{eV} \cdot \mathrm{e}^{-1}$ vs. $10.2 \mathrm{eV} \cdot \mathrm{e}^{-1}$ using the revised scale of electronegativity. ${ }^{67}$

ii The solid electrolyte inductive effect model of Krauskopf et al. ${ }^{35}$ borrows from the general concept of an inductive effect, which has been used to explain trends in a number of properties within classes of functional materials. $^{68,69}$
} 
Coulombic interaction between $S$ and adjacent Li ions. In the LGPS structure, the Li(3) site is closer to the $(M / P) S_{4}$ tetrahedra than the Li(1) site, which stabilizes Li occupation of the Li(3) site relative to occupation of the Li(1) site, producing an increased potential energy barrier for lithium diffusion.

Together with the proposal by Krauskopf et al. ${ }^{35}$ that an inductive effect might explain the observed lithium conductivity trend in $\mathrm{Li}_{10} M \mathrm{P}_{2} \mathrm{~S}_{12}$, solid-electrolyte inductive effects have been invoked to explain anomalous conductivity trends in a number of other systems, ${ }^{37}$ including $\mathrm{Na}_{11} \mathrm{Sn}_{2} P n \mathrm{~S}_{12}(P n=\mathrm{P}, \mathrm{Sb}),{ }^{38} \mathrm{Na}_{3} \mathrm{P}_{1-x} \mathrm{As}_{x} \mathrm{~S}_{4},{ }^{39}$ and $\mathrm{Li}_{2}\left(\mathrm{PO}_{4}\right)_{3}(M=\mathrm{Zr}, \mathrm{Sn}) .^{40}$ The solidelectrolyte inductive-effect model is founded on simple chemical-bonding concepts, making it an appealing model for explaining these unexpected conductivity trends. Yet there is no direct evidence that such an inductive effect does in fact exist. More specifically, it is not known to what extent varying the electronegativities of host-framework atoms within a solid electrolyte can affect either the intra-framework bonding interactions or the electrostatic interactions between the host framework and the mobile ions; nor is it clear whether such effects, if present, can modify ionic conductivities sufficiently to explain observed trends in solid-electrolyte conductivities.

Motivated by the question of whether the solid-electrolyte inductive effect does indeed exist, we have performed a combined experimental and computational study of the $\mathrm{Li}_{10} \mathrm{Ge}_{1-x} \mathrm{Sn}_{x} \mathrm{P}_{2} \mathrm{~S}_{12}$ system. This study reveals a series of subtle structural and electronic changes produced by $\mathrm{Ge}^{4+}$ $\rightarrow \mathrm{Sn}^{4+}$ substitution that are consistent with the model proposed by Krauskopf et al. ${ }^{35}$ Data from Raman spectroscopy and density functional theory (DFT) calculations show that the inclusion of lower-electronegativity $\mathrm{Sn}$ produces weaker (more polar) $M-\mathrm{S}$ bonds within the $M_{\mathrm{S}_{4}}{ }^{4-}$ tetrahedra, and Rietveld refinements against high-resolution temperature-dependent neutrondiffraction data show that this decrease in $M-\mathrm{S}$ bond strength is correlated with shorter $\mathrm{S}^{2-}-\mathrm{Li}^{+}$ distances and increased $\mathrm{Li}^{+}$site-occupation around the $\mathrm{S}^{2-}$ ions, which suggests a stronger $\mathrm{S}^{2-}$ $\cdots \mathrm{Li}^{+}$interaction in the Sn-substituted system. DFT calculated lithium-binding energies provide further complementary evidence that Sn-substitution increases the strength of the $\mathrm{S}^{2-\cdots} \mathrm{Li}^{+}$ interactions. Our DFT calculations also show that these changes in $M-\mathrm{S}$ bonding and $\mathrm{S}^{2-} \cdots \mathrm{Li}^{+}$ interactions are coupled to a modulation of the $\mathrm{Li}^{+}$potential-energy profile along the $\mathrm{Li}(3)-$ $\mathrm{Li}(1)$ diffusion pathway in the channels: substituting $\mathrm{Ge}^{4+}$ for $\mathrm{Sn}^{4+}$ gives a higher potentialenergy maximum for single-lithium-ion motion. Further calculations for the Sn-substituted 
system, but with a fixed geometry corresponding to the Ge-substituted analogue, show that $\mathrm{Sn}$ substitution increases the height of the $\mathrm{Li}^{+}$diffusion profile even in the absence of changes in host-framework geometry, providing further evidence for an electronic inductive effect.

When considered together, these results provide compelling evidence in support of a solidelectrolyte inductive effect in the $\mathrm{Li}_{10} \mathrm{Ge}_{1-x} \mathrm{Sn}_{x} \mathrm{P}_{2} \mathrm{~S}_{12}$ system. These data also illustrate how information about subtle changes in host-framework bonding and framework-mobile-ion interactions arising from framework-atom substitution can be obtained through a combination of experimental and computational techniques, and how this can provide a clearer understanding of the chemical effects responsible for modulating ionic conductivities in families of structurally-similar lithium-ion solid electrolytes.

\section{Experimental Methods}

Synthesis. All preparations and sample treatments were carried out under argon atmosphere $\left(\mathrm{O}_{2}<1 \mathrm{ppm}, \mathrm{H}_{2} \mathrm{O}<5 \mathrm{ppm}\right) . \mathrm{Li}_{10} \mathrm{Ge}_{1-x} \mathrm{Sn}_{x} \mathrm{P}_{2} \mathrm{~S}_{12}$ was synthesized using the following procedure: the starting materials of lithium sulfide ( $\mathrm{Li}_{2} \mathrm{~S}$, Sigma Aldrich, 99.98\%), phosphorus pentasulfide $\left(\mathrm{P}_{2} \mathrm{~S}_{5}\right.$, Sigma-Aldrich, 99\%), elemental sulfur ( $\mathrm{S}_{8}$, Arcos Organics, $\left.>99.999 \%\right)$, germanium sulfide (GeS, Sigma-Aldrich, 99.99\%) and tin sulfide (SnS, Sigma-Aldrich, > 99.99\%) were mixed in the appropriate stoichiometric ratio. Additionally, a $3 w t \%$ excess of sulfur was added to the mixture to compensate for sulfur loss at higher temperatures. The resulting mixture $(3 \mathrm{~g})$ was ball-milled (Fritsch Pulverisette 7 premium line) at $400 \mathrm{rpm}$ using a $\mathrm{ZrO}_{2}$ milling set ( $80 \mathrm{~mL}$ bowl with $90 \mathrm{~g}$ of $3 \mathrm{~mm}$ diameter milling media). The milling was performed for $48 \mathrm{~h}$ with intermediate cooling times (i.e. $15 \mathrm{~min}$ of cooling after every $10 \mathrm{~min}$ of milling) to prevent excessive heating of the samples. Twice during this process, the grinding bowl was opened, and the resultant mixture was ground to obtain a uniform precursor. The resultant precursor $(1 \mathrm{~g})$ was pressed into pellets, which were then sealed under vacuum into $10 \mathrm{~mm}$ inner-diameter quartz ampoules. The ampoules were heated in a tube furnace to $773 \mathrm{~K}$ (at $27 \mathrm{~K} \mathrm{~h}^{-1}$ ), annealed for $20 \mathrm{~h}$ and then cooled to room temperature. To reduce the formation of side-phases in $\mathrm{Li}_{10} \mathrm{SnP}_{2} \mathrm{~S}_{12}$, this pellet was reheated at $873 \mathrm{~K}$ for $48 \mathrm{~h}\left(\right.$ at $\left.50 \mathrm{~K} \mathrm{~h}^{-1}\right)$.

Neutron Powder Diffraction. Neutron powder diffraction data were collected using the

Spallation Neutron Source (SNS) POWGEN diffractometer at Oak Ridge National Laboratory.$^{41}$ Approximately $3 \mathrm{~g}$ of sample were loaded into an $8 \mathrm{~mm}$ diameter cylindrical 
vanadium sample can. Using a center wavelength of $0.8 \AA$ with a $d$-spacing from $0.2 \AA$ to $6.0 \AA$, data were collected for approximately $3 \mathrm{~h}$ in the high-resolution mode at each temperature.

Rietveld Analysis. Rietveld refinements were carried out using the TOPAS-Academic V6 software package, ${ }^{42}$ using a convolution of back-to-back exponential and the Thompson-CoxHastings pseudo-Voigt function for the profiles. The following parameters were initially refined: (1) scale factor, (2) background coefficients, (3) peak shape, (4) lattice constants, (5) fractional atomic coordinates and (6) isotropic atomic displacement parameters. Additionally, Sn was allowed to occupy the Wyckoff $4 d$ positions and constrained to the value of $g(\mathrm{Ge})+$ $g(\mathrm{Sn})=0.5$. Bond-lengths and polyhedral volumes were extracted from the Vesta software package (Version 3). ${ }^{43}$

Raman Analysis. Raman spectra were collected using a Senterra Raman spectrometer (Bruker) with an excitation wavelength of $532 \mathrm{~nm}$. Data collection was performed in a spectral range from $55 \mathrm{~cm}^{-1}$ to $1555 \mathrm{~cm}^{-1}$ using a $20 \times$ objective and a power of $0.2 \mathrm{~mW}$. The powder samples were placed on glass substrates inside a glovebox, framed with silicone vacuum grease, and were sealed airtight with a cover glass to ensure inert atmosphere during measurement.

Computational Methods. All density functional theory (DFT) calculations were performed using VASP ${ }^{4-46}$ with valence electrons described by a plane-wave basis. Interactions between core and valence electrons were described using the Projector Augmented Wave (PAW) method with valence electron configurations of $\mathrm{Li}\left[2 \mathrm{~s}^{1}\right], \mathrm{Ge}\left[4 \mathrm{~s}^{2} 4 \mathrm{p}^{2}\right], \mathrm{Sn}\left[5 \mathrm{~s}^{2} 5 \mathrm{p}^{2}\right], \mathrm{P}\left[3 \mathrm{~s}^{2} 3 \mathrm{p}^{3}\right]$, and S $\left[3 s^{2} 3 p^{4}\right] .{ }^{47}$ All calculations used the Generalized Gradient Approximation (GGA) functional PBEsol. ${ }^{48}$ Calculations with a fixed cell volume used a plane-wave cutoff of $500 \mathrm{eV}$, while calculations with a variable cell volume used an increased cutoff of $650 \mathrm{eV}$ to minimize errors due to Pulay stress. Geometry optimizations were deemed converged when all atomic forces were smaller than $0.01 \mathrm{eV}^{-1}$. All calculations were spin-polarized and used a Monkhorst-Pack grid for sampling $\boldsymbol{k}$-space, with the minimum spacing between $\boldsymbol{k}$-points set to $0.3 \AA^{-1}$.

To quantify charge distributions and bonding characters from our DFT calculations, we assign net atomic-charges, calculated using the DDEC6 methodology as implemented in the CHARGEMOL package, ${ }^{49}$ and Crystal-Orbital Hamilton Populations (iCOHP), calculated using the LOBSTER code..$^{50-52}$ Within LOBSTER, the vaspfitpbe2015 basis functions were used to map 
the VASP plane-wave basis-set onto local orbitals. To sample single-lithium-ion diffusion potential-energy profiles along the $c$ channels, we performed climbing-image nudged-elasticband $(\mathrm{CI}-\mathrm{NEB})^{53}$ calculations, using the pathfinder algorithm of Rong et al..$^{54}$ to obtain an initial approximation of each minimum-energy-barrier path.

To estimate changes in the $\mathrm{S}-\mathrm{Li}$ interaction for $M=\mathrm{Sn}, \mathrm{Ge}$, we calculated "vertical" (unrelaxed) $\mathrm{Li}^{+}$vacancy formation energies $\left(E_{\mathrm{f}}^{V_{\mathrm{Li}}^{\prime}}\right)$ for all $\mathrm{Li}$ atoms as a function of nearest-neighbor $\mathrm{Li}-\mathrm{S}$ distance, with reference to the $\mathrm{S}$ atoms that constitute the vertices of the $\mathrm{SnS}_{4}{ }^{4-}$ tetrahedra. The $\mathrm{Li}^{+}$vacancy formation energies, $E_{\mathrm{f}}^{V_{\mathrm{Li}}^{\prime}}$, were calculated as

$$
E_{\mathrm{f}}^{V_{\mathrm{Li}}^{\prime}}=\Delta E^{V_{\mathrm{Li}}^{\prime}}+\mu_{\mathrm{Li}}-E_{\mathrm{F}},
$$

where $\Delta E^{V_{\mathrm{Li}}^{\prime}}$ is given by the difference in energy between a stoichiometric defect-free supercell and an equivalent cell containing a single $\mathrm{Li}^{+}$vacancy, with all other atoms held fixed in place. $\mu_{\mathrm{Li}}$ is the chemical potential of the Li atom to be removed from the cell, and $E_{\mathrm{F}}$ is the chemical potential of the electron to be added (Fermi energy), referenced to the valence band maximum, with the bulk electrostatic potentials of the defect and pristine cell aligned. ${ }^{55}$

Calculations of formation energies of charged defects using periodic models, as for the $\mathrm{Li}^{+}$ vacancy considered here, typically include an image-charge energy term $\left(E_{\text {icc }}\right)$, to correct for a shift in total energy due to the artificial interaction of a defect with its periodic images. This correction requires calculation of the dielectric tensor, which is ill-defined within a DFT framework for an intrinsically disordered system such as LGPS. For the results presented here, we do not include an explicit image-charge correction, and instead attempt to minimize the variation in the neglected correction term - which scales approximately as $L^{-3}$, where $L$ is the length of the simulation cell ${ }^{56}$ - by performing our defect calculations in large 400 atom $2 \times 2 \times 2 \mathrm{Li}_{10} \mathrm{GeP}_{2} \mathrm{~S}_{12}$ supercells. We have estimated the magnitude of the (neglected) imagecharge correction term by performing an explicit calculation for a $V_{\mathrm{Li}}^{\prime}$ vacancy in a pseudoordered structure of $\mathrm{Li}_{10} \mathrm{GeP}_{2} \mathrm{~S}_{12}$ taken from the Materials Project, ${ }^{57}$ using the approach of Lany and Zunger, ${ }^{55}$ which gives a representative value of $E_{\text {icc }}=0.05 \mathrm{eV}$.

Because $\mathrm{Li}_{10} \mathrm{GeP}_{2} \mathrm{~S}_{12}$ is intrinsically lithium-disordered, the Li-S interaction may not be well characterized by considering a single lithium-vacancy formation-energy. To account for this lithium disorder, we have sampled the distribution of vacancy-formation-energies as a 
function of S-Li distance from a set of 160 lithium configurations. These representative 160 configurations were selected from an initial set of 500000 structures, with candidate structures selected by ranking their approximate electrostatic energies, using the Ewald summation functionality in the PYMATGEN package..$^{58}$

A data set containing DFT calculation inputs and outputs is available at the University of Bath Data Archive, published under the CC-BY-4.0 license. ${ }^{59}$ The dataset also includes analysis scripts, published under the MIT license, used to post-process the DFT data and to plot Figures $4,6 b$, and 7 . The data analysis scripts use the Python packages PYMATGEN, ${ }^{58}$ NUMPY ${ }^{60}$ PANDAS, ${ }^{61}$ and MATPLOTLIB. ${ }^{62}$

\section{Results}

General structural characterization. To characterize the influence of $\mathrm{Ge}^{4+} \rightarrow \mathrm{Sn}^{4+}$ substitution in the $\mathrm{Li}_{10} \mathrm{Ge}_{1-x} \mathrm{Sn}_{x} \mathrm{P}_{2} \mathrm{~S}_{12}$ series, compounds were synthesized with four varying stoichiometries - nominally $x=0,0.33,0.67$, and 1 . Because of the low X-ray form-factor of $\mathrm{Li}^{+}$, high-resolution neutron diffraction data were collected in the temperature range of $300 \mathrm{~K}$ to $500 \mathrm{~K}$ to allow the subtle effects of $\mathrm{Sn}$-substitution on the lithium substructure to be resolved. Representative Rietveld refinements of the room-temperature neutron diffraction data for the $\mathrm{Li}_{10} \mathrm{Ge}_{1-x} \mathrm{Sn}_{x} \mathrm{P}_{2} \mathrm{~S}_{12}$ compounds are shown in Figure $\mathrm{S} 1$. All constraints used in the refinements are tabulated in Table S1 and the resulting structures at all temperatures are included as crystallographic information format (CIF) files in the Supporting Information. The reflections within the isostructural $\mathrm{Li}_{10} \mathrm{Ge}_{1-x} \mathrm{Sn}_{x} \mathrm{P}_{2} \mathrm{~S}_{12}$ patterns were indexed to the tetragonal $\mathrm{Li}_{10} \mathrm{Ge}_{1-x} \mathrm{Sn}_{x} \mathrm{P}_{2} \mathrm{~S}_{12}$ structure, crystallizing in the $P 4_{2} / n m c$ space group. The room-temperature structural data (Figure S2a) show that substitution of the larger $\mathrm{Sn}^{4+}$ cation $(0.55 \AA)$ for $\mathrm{Ge}^{4+}$ $(0.39 \AA)$ within a tetrahedral coordination environment ${ }^{63}$ causes linear increases in the lattice parameters $a$ and $c$, in the $c / a$-ratio of the tetragonal unit cell, and in the unit cell volume. Thus, Vegard's law is obeyed, confirming the successful synthesis of homogeneous solid solutions. With increasing temperature, the lattice parameters and unit-cell volumes increase linearly, while the $c / a$ ratios decrease (Figure S2b), in good agreement with literature data. ${ }^{23}$

Bond-strength indicators and changing $\boldsymbol{M}-\mathbf{S}$ bonding interactions. The linear increase in $\mathrm{Li}_{10} \mathrm{Ge}_{1-x} \mathrm{Sn}_{x} \mathrm{P}_{2} \mathrm{~S}_{12}$ unit-cell volume with increasing $\mathrm{Sn}$ content is mirrored by an increased $(M / \mathrm{P}) \mathrm{S}_{4}$ tetrahedral volume and an increased $M-\mathrm{S}$ bond distance (Figure $\left.3 \mathrm{a}\right)$. This increased 
bond distance suggests that $\mathrm{Ge}^{4+} \rightarrow \mathrm{Sn}^{4+}$ substitution causes a decrease in $M-\mathrm{S}$ bond strength. The Raman spectra for the $\mathrm{Li}_{10} \mathrm{Ge}_{1-x} \mathrm{Sn}_{x} \mathrm{P}_{2} \mathrm{~S}_{12}$ series (Figure S3) support this interpretation; while the Raman shift for the symmetric stretching mode of the $\mathrm{PS}_{4}{ }^{3-}$ units remains unchanged throughout the series, the analogous vibrational mode of the $\mathrm{SnS}_{4}{ }^{4-}$ units, $v_{1}\left(A_{1}\right)$, is consistently observed at lower wavenumbers relative to the $\mathrm{GeS}_{4}{ }^{4-}$ units. This behavior can be attributed both to the changes in bond-lengths and to the difference in electronegativity between Ge and Sn. Considering the $M-\mathrm{S}$ bond in the $\mathrm{MS}_{4}{ }^{4-}$ tetrahedra as a harmonic spring, the force constant $K$ can be related to the Raman shift via ${ }^{64}$

$$
K=(2 \pi \tilde{v} c)^{2} \mu,
$$

where $\tilde{v}$ is the Raman shift and $\mu$ is the reduced mass. Because the central atoms $M$ are at rest during the symmetric $A_{1}$ stretches of the $\mathrm{GeS}_{4}{ }^{4-}$ and $\mathrm{SnS}_{4}{ }^{4-}$ tetrahedra, $\mu$ can be replaced by the mass of $\mathrm{S},{ }^{64}$ which allows the observed Raman shifts across the $\mathrm{Li}_{10} \mathrm{Ge}_{1-x} \mathrm{Sn}_{x} \mathrm{P}_{2} \mathrm{~S}_{12}$ series to be expressed as force constants for the $A_{1}$ vibration modes. To account for changes in the $\mathrm{Ge} / \mathrm{Sn}$ ratios, and thus for changes in the relative contributions to each vibration, we have reweighted these force constants based on the Rietveld-refined compositions to obtain an averaged descriptor. Increasing Sn content is associated with a decrease in the weighted force-constant (Figure $3 \mathrm{~b}$ ), which is consistent with a corresponding decrease in average $M-\mathrm{S}$ bond-strength. As a complementary measure, we also consider the Debye frequencies for the $\mathrm{Li}_{10} \mathrm{Ge}_{1-x} \mathrm{Sn}_{x} \mathrm{P}_{2} \mathrm{~S}_{12}$ series (Figure 3b), which describe an "average bond-strength" for each composition. ${ }^{35}$ The decrease in the Debye frequency with increasing Sn content is consistent with the trend observed for the Raman-spectra-derived force constants and further supports the proposition that $\mathrm{Ge} \rightarrow \mathrm{Sn}$ substitution decreases the strength of $M-\mathrm{S}$ bonds in $\mathrm{Li}_{10} \mathrm{Ge}_{1-x} \mathrm{Sn}_{x} \mathrm{P}_{2} \mathrm{~S}_{12}$.
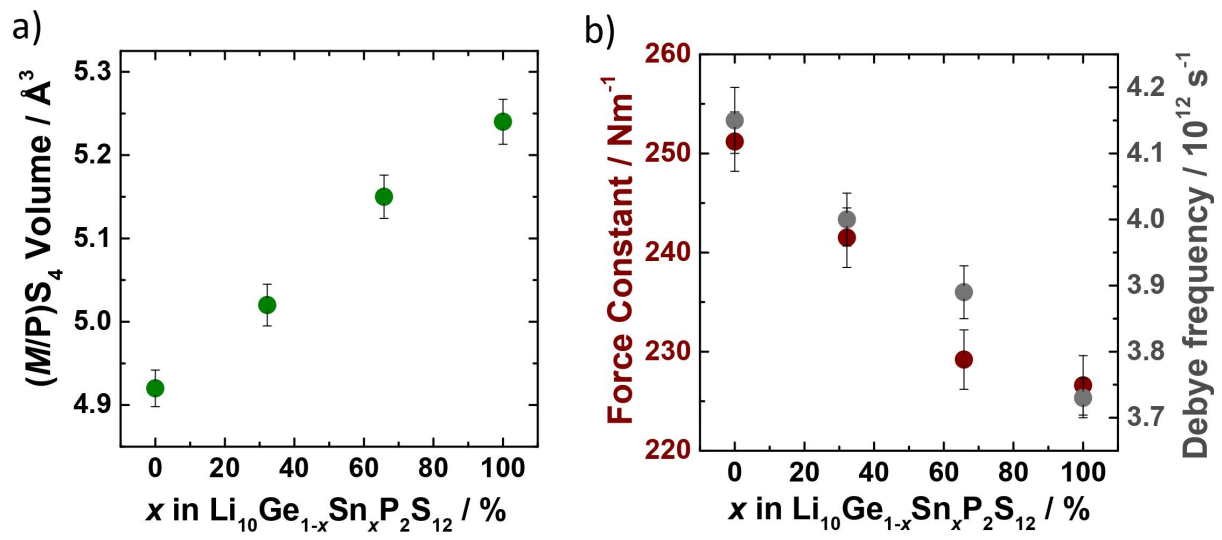

Figure 3: Bond strength indicators in $\mathrm{Li}_{10} G e_{1-x} \mathrm{Sn}_{x} P_{2} S_{12}$. (a) Temperature-averaged $(M / P) S_{4}$ polyhedral volumes and (b) weighted averaged force constants of the $M S_{4}$ tetrahedra (dark red) 
and the Debye frequencies (literature values from reference 35, dark gray) for $\mathrm{Li}_{10} G e_{1-x} \mathrm{Sn}_{x} P_{2} S_{12}$ are also provided.

To explore how the choice of $M=\{\mathrm{Ge}, \mathrm{Sn}\}$ affects the $M-\mathrm{S}$ bonding character, we have calculated integrated crystal-orbital Hamilton populations (iCOHPs) for the $M-\mathrm{S}$ bonds in $\mathrm{Li}_{10} \mathrm{Ge}_{0.5} \mathrm{Sn}_{0.5} \mathrm{P}_{2} \mathrm{~S}_{12}$. These iCOHP values are plotted in Figure $4 \mathrm{a}$, and are indicative of bonding strength within the respective $M S_{4}$ tetrahedra: more negative values indicate stronger and morecovalent bonding, while more positive values indicate weaker and more polar bonding. ${ }^{50-52}$ The more negative values obtained for the $\mathrm{GeS}_{4}$ tetrahedra compared to the $\mathrm{SnS}_{4}$ tetrahedra suggest stronger bonding interactions for these $\mathrm{Ge}-\mathrm{S}$ bonds compared to the equivalent $\mathrm{Sn}-\mathrm{S}$ bonds, which agrees with the trends observed for the $M-\mathrm{S}$ force constants and Debye frequencies.

To investigate whether these changes in bond-strength are coupled to a measurable change in the charge density associated with the $M$-bonded $\mathrm{S}$ ions, we have also calculated net atomiccharges for the $\mathrm{Li}_{10} \mathrm{GeP}_{2} \mathrm{~S}_{12}$ and $\mathrm{Li}_{10} \mathrm{SnP}_{2} \mathrm{~S}_{12}$ end-members (Figure $4 \mathrm{~b}$ ), This analysis assigns larger more-negative charges to $\mathrm{Sn}$-bonded $\mathrm{S}$ ions in $\mathrm{Li}_{10} \mathrm{SnP}_{2} \mathrm{~S}_{12}$ than to equivalent Ge-bonded $\mathrm{S}$ ions in $\mathrm{Li}_{10} \mathrm{GeP}_{2} \mathrm{~S}_{12}$. To quantify the $M-\mathrm{S}$ bond polarity in $\mathrm{Li}_{10} \mathrm{GeP}_{2} \mathrm{~S}_{12}$ and $\mathrm{Li}_{10} \mathrm{SnP}_{2} \mathrm{~S}_{12}$, we computed the differences in net atomic-charge values between the $\mathrm{Ge}$ or $\mathrm{Sn}$ ions and their coordinating $\mathrm{S}$ ions. We again find a subtle but clear difference in bonding character between these two end-members, with the $\mathrm{Ge}-\mathrm{S}$ bonds in $\mathrm{Li}_{10} \mathrm{GeP}_{2} \mathrm{~S}_{12}$ being less polar in character than the $\mathrm{Sn}-\mathrm{S}$ bonds in $\mathrm{Li}_{10} \mathrm{SnP}_{2} \mathrm{~S}_{12}$.

These bond-strength indicators (bond-stretch force constants and iCOHP values) and bond polarity data (net atomic-charges) together give a coherent picture of how substituting Sn for Ge in $\mathrm{Li}_{10} M \mathrm{P}_{2} \mathrm{~S}_{12}$ affects the $M-\mathrm{S}$ bonding. $\mathrm{Ge}-\mathrm{S}$ bonding is stronger and less polar than $\mathrm{Sn}-\mathrm{S}$ bonding and $\mathrm{Ge}$-bonded $\mathrm{S}$ atoms in $\mathrm{Li}_{10} \mathrm{GeP}_{2} \mathrm{~S}_{12}$ have smaller (less negative) associated charges than $\mathrm{Sn}$-bonded $\mathrm{S}$ atoms in $\mathrm{Li}_{10} \mathrm{SnP}_{2} \mathrm{~S}_{12}$. Each of these observations is consistent with the predictions of the inductive effect model. 

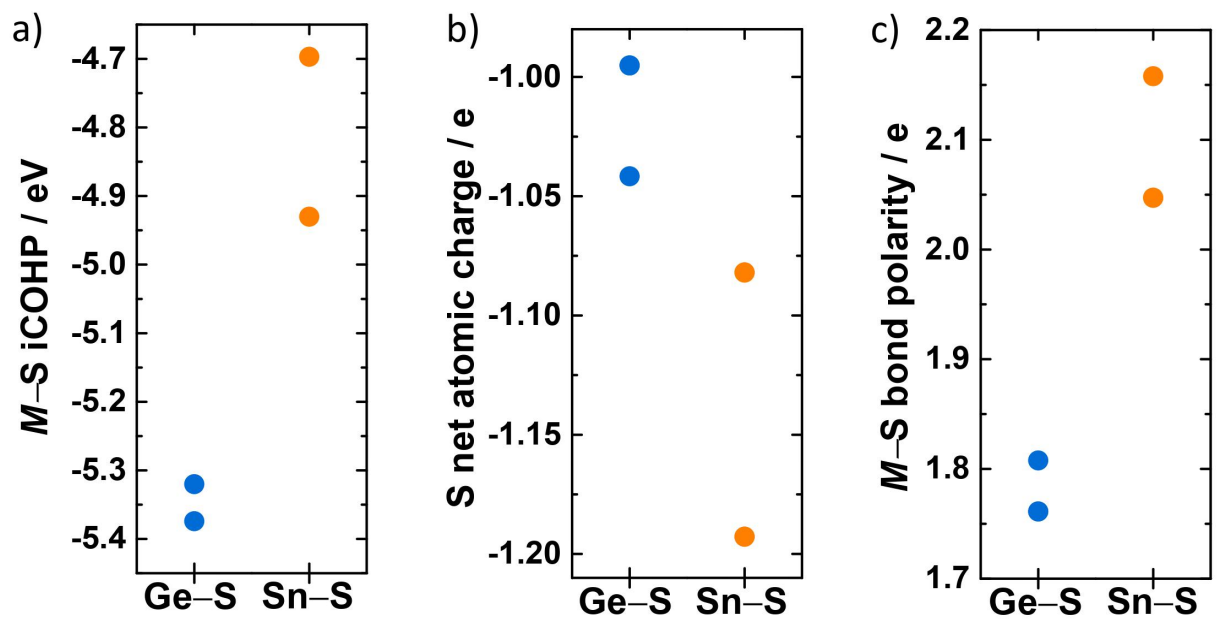

Figure 4: a) M-S integrated crystal-orbital Hamilton populations (iCOHP) calculated for $L i_{10} M P_{2} S_{12}(M=G e, S n)$, (b) sulfur net atomic charges (NAC), and (c) M-S bond polarities. Consistently higher net atomic charges on sulfur can be found for $M=$ Sn which is correlated to a weaker bonding interaction between $S n$ and $S$ relative to Ge and $S$.

Modulating S-Li interactions and the effect on the $\mathbf{L i}^{+}$substructure. Our DFT calculations, discussed above, predict that $\mathrm{S}(2)$ atoms carry more negative charge when bonded to Sn than to Ge. This increased negative charge is expected to correspond to a stronger Coulombic interaction between these $S(2)$ atoms and nearby lithium ions, which may cause a change in the lithium-ion substructure. The $c$-oriented lithium diffusion pathway consists of alternating $\operatorname{Li}(1)$ and $\operatorname{Li}(3)$ sites, with the $\operatorname{Li}(3)$ sites closest to the $\mathrm{S}(2)$ framework atoms. We would therefore expect that a change in the $\mathrm{S}(2) \cdots \mathrm{Li}$ interaction with increasing Sn content would most strongly affect lithium occupying the $\operatorname{Li}(3)$ sites compared to lithium occupying the more distant $\operatorname{Li}(1)$ sites.

Figures $5 \mathrm{a}$ and $5 \mathrm{~b}$ show plots of the $\mathrm{S}(2)-\operatorname{Li}(1)$ and $\mathrm{S}(2)-\operatorname{Li}(3)$ distances and the $\operatorname{Li}(1)$ and $\operatorname{Li}(3)$ percentile-occupancies as functions of $x(\mathrm{Sn})$, as obtained from Rietveld refinements against neutron-diffraction data. These plots show temperature-averaged data to highlight the persistence of the observed trends across the studied temperature range. The full dataset containing values obtained at each temperature is included in the Supporting Information (Figure S4). 

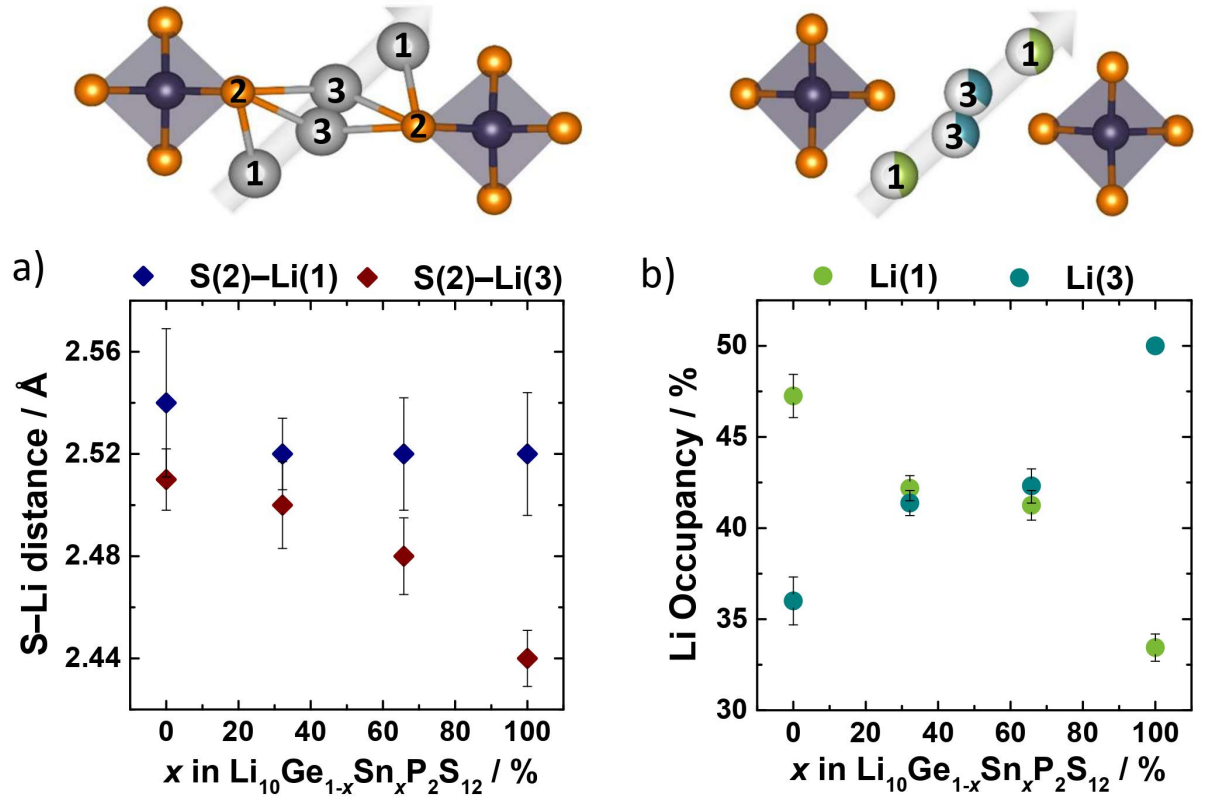

Figure 5: Variation in lithium substructure with Sn content in $\mathrm{Li}_{10} G e_{1-x} S n_{x} P_{2} S_{12}$. (a) the $S(2)$ Li(1) and S(2)-Li(3) distances and (b) Li(1), Li(3) occupancies along the main diffusion channel. All shown data obtained from the refinements at $300 \mathrm{~K}, 375 \mathrm{~K}, 450 \mathrm{~K}$, and $500 \mathrm{~K}$ have been averaged for visual clarity and to highlight the persistence of the trends within the studied temperature range. Error bars show the standard deviations for these data when combining all temperatures.

As the $\mathrm{Sn}$ content increases, the $\mathrm{S}(2)-\operatorname{Li}(3)$ distance decreases, while the $\mathrm{S}(2)-\mathrm{Li}(1)$ distance is largely unchanged (Figure 5a). This is consistent with the expectation that changes in the $S(2)$ charge density affect neighboring $\operatorname{Li}(3)$ lithium ions more strongly than more distant $\operatorname{Li}(1)$ lithium ions. Increasing the degree of Sn-substitution also produces an increase in the $\mathrm{Li}(3)$ siteoccupancy and a corresponding decrease in the $\operatorname{Li}(1)$ site occupancy (Figure 5b). This redistribution of lithium ions from $\operatorname{Li}(1)$ to $\mathrm{Li}(3)$ sites is also consistent with a picture of lithiumions being more strongly attracted to $\mathrm{Li}(3)$ sites versus $\mathrm{Li}(1)$ sites as $\mathrm{Ge}$ is progressively substituted by $\mathrm{Sn}$.

$\mathrm{Ge} \rightarrow$ Sn substitution effects on the $\mathrm{Li}^{+}$-ion potential energy surface. To corroborate the stabilizing effect of Sn-substitution on Li ions occupying nearby $\mathrm{Li}(3)$ sites, we performed a further series of DFT calculations in which we computed the $\mathrm{Li}^{+}$vacancy-formation energies $\left(E_{\mathrm{f}}^{V_{\mathrm{Li}}^{\prime}}\right)$ for a set of $\mathrm{Li}_{10} \mathrm{GeP}_{2} \mathrm{~S}_{12}$ supercells each containing one $\mathrm{Sn}$ ion. These $\mathrm{Li}^{+}$vacancyformation energies give a relative measure of the "binding energy" of $\mathrm{Li}^{+}$at different positions 
within each supercell; a larger vacancy-formation energy corresponds to a more stable $\mathrm{Li}^{+}$ position. Figure $6 \mathrm{a}$ shows the resulting distributions of calculated $\mathrm{Li}^{+}$vacancy-formation energies, classified according to whether the $\mathrm{Li}^{+}$ion removed is originally located less than 3 $\AA$ of a Sn-bonded S(2) atom or not. The vacancy-formation-energies for Li ions close to Snbonded $S(2)$ atoms are shifted to higher energies relative to the vacancy-formation-energies for $\mathrm{Li}$ ions that sit further away, i.e. there is a greater energy cost to remove lithium ions from $\mathrm{Sn}-$ $\mathrm{S}(2)$-adjacent positions. This agrees with the interpretation of our neutron diffraction refinement data that $\mathrm{Li}$ ions are indeed more strongly bound to $\mathrm{S}$ in $\mathrm{SnS}_{4}{ }^{4-}$ tetrahedra than to $\mathrm{S}$ in $\mathrm{GeS}_{4}{ }^{4-}$ tetrahedra.

Because the primary diffusion channels in $\mathrm{Li}_{10} \mathrm{Ge}_{1-x} \mathrm{Sn}_{x} \mathrm{P}_{2} \mathrm{~S}_{12}$ are comprised of alternating $\mathrm{Li}(3)$ and $\mathrm{Li}(1)$ sites, the enhanced binding of $\mathrm{Li}^{+}$ions at $\mathrm{Li}(3)$ sites versus $\mathrm{Li}(1)$ sites with increasing Sn content is expected to correspond to a modulation of the potential energy profile for Li ions moving within these $c$-oriented diffusion channels. To better quantify the effect of $\mathrm{Ge} \rightarrow$ Sn substitution on the Li-ion potential-energy profile along the $\mathrm{Li}(3)-\mathrm{Li}(1)$ diffusion channels, we consider potential energy profiles obtained from a series climbing-image nudged elastic band (c-NEB) calculations for a single $\mathrm{Li}^{+}$ion moving from the $\mathrm{Li}(3)$ site to the $\mathrm{Li}(1)$ site. $\mathrm{Li}$ diffusion in $\mathrm{Li}_{10} \mathrm{GeP}_{2} \mathrm{~S}_{12}$ proceeds by the concerted string-like motion of groups of lithium ions,${ }^{65}$ and NEB pathways for individual lithium ions therefore should not be equated with the true microscopic free-energy-barrier for lithium motion (which determines the activation energy for $\mathrm{Li}^{+}$conduction). In this case, however, we are interested in local differences in the potential energy surfaces as a function of $\mathrm{Ge} \rightarrow \mathrm{Sn}$ substitution, and we consider these single- $\mathrm{Li}^{+} \mathrm{NEB}$ barriers as a proxy metric for the "roughness" of the true manybody potential-energy surface. The c-NEB profiles for $\mathrm{Li}^{+}$diffusion in $\mathrm{Li}_{10} \mathrm{GeP}_{2} \mathrm{~S}_{12}$ and in $\mathrm{Li}_{10} \mathrm{SnP}_{2} \mathrm{~S}_{12}$ are shown in Figure 6b. These profiles were computed following the standard cNEB procedure, allowing all images along the diffusion path to fully relax within the c-NEB constraints. These "relaxed" c-NEB profiles show a larger potential energy barrier for $\operatorname{Li}(3)$ $\rightarrow \mathrm{Li}(1) \mathrm{Li}$-movement in $\mathrm{Li}_{10} \mathrm{SnP}_{2} \mathrm{~S}_{12}$ than in $\mathrm{Li}_{10} \mathrm{GeP}_{2} \mathrm{~S}_{12}$, in agreement with conductivity trends from experiment and diffusion coefficients from previous molecular dynamics simulations of $\mathrm{Li}_{10}(\mathrm{GeSn}) \mathrm{P}_{2} \mathrm{~S}_{12}{ }^{21}$ This result, again, agrees with the qualitative predictions of the solid-electrolyte inductive effect model. 
Decoupling geometric and electronic effects of $\mathbf{G e} \rightarrow$ Sn substitution. The substitution of Ge for $\mathrm{Sn}$ in $\mathrm{Li}_{10} \mathrm{GeP}_{2} \mathrm{~S}_{12}$ does not only affect the chemical bonding and charge distribution within the host-framework; it also changes the host-framework geometry. It is therefore possible that even though our data provide strong evidence for a solid-electrolyte inductive effect in $\mathrm{Li}_{10} \mathrm{Ge}_{1-x} \mathrm{Sn}_{x} \mathrm{P}_{2} \mathrm{~S}_{12}$, this might not be the cause of the conductivity trend observed in experiment-instead the observed effect may be due to the geometric effects of $\mathrm{Ge} \rightarrow \mathrm{Sn}$ substitution. ${ }^{35}$ To resolve the electronic and geometric contributions to the potential-energybarrier difference predicted for our fully-relaxed c-NEB calculations, we performed a second set of calculations with $\mathrm{Sn}$ fully substituted into $\mathrm{Li}_{10} \mathrm{GeP}_{2} \mathrm{~S}_{12}$ and Ge fully substituted into $\mathrm{Li}_{10} \mathrm{SnP}_{2} \mathrm{~S}_{12}$, and with each image along the diffusion pathway held fixed at the original geometry. In other words, we compute an approximate barrier for $\mathrm{Li}_{10} \mathrm{SnP}_{2} \mathrm{~S}_{12}$ fixed at the optimized $\mathrm{Li}_{10} \mathrm{GeP}_{2} \mathrm{~S}_{12}$ geometries, and for $\mathrm{Li}_{10} \mathrm{GeP}_{2} \mathrm{~S}_{12}$ fixed at the optimized $\mathrm{Li}_{10} \mathrm{SnP}_{2} \mathrm{~S}_{12}$ geometries. If the relative potential energy barriers for $\mathrm{Li}_{10} \mathrm{GeP}_{2} \mathrm{~S}_{12}$ and for $\mathrm{Li}_{10} \mathrm{SnP}_{2} \mathrm{~S}_{12}$ depend only on the difference in host-framework geometry produced by $\mathrm{Ge} \rightarrow \mathrm{Sn}$ substitution, we would expect the relative barriers from these cation-exchanged fixed-geometry calculations to give a lower barrier for $\mathrm{Li}_{10} \mathrm{SnP}_{2} \mathrm{~S}_{12}$ (computed using the optimized $\mathrm{Li}_{10} \mathrm{GeP}_{2} \mathrm{~S}_{12}$ geometries), and a higher barrier for $\mathrm{Li}_{10} \mathrm{GeP}_{2} \mathrm{~S}_{12}$ (computed using the optimized $\mathrm{Li}_{10} \mathrm{SnP}_{2} \mathrm{~S}_{12}$ geometries). Instead we see the opposite trend (Figure 6c). The approximate potential-energy barrier is higher for $\mathrm{Li}_{10} \mathrm{SnP}_{2} \mathrm{~S}_{12}$ even when the geometry of the diffusion pathway is that of fully relaxed $\mathrm{Li}_{10} \mathrm{GeP}_{2} \mathrm{~S}_{12}$. Providing these $\mathrm{Li}$-ion potential energy barriers are effective descriptors of the variation in the true many-body free-energy surface in $\mathrm{Li}_{10} \mathrm{Ge}_{1-x} \mathrm{Sn}_{x} \mathrm{P}_{2} \mathrm{~S}_{12}$, this result suggests that the observed conductivity trend cannot be attributed solely to geometric effects, and that electronic effects, such as those described by the solid-electrolyte inductive effect model, have an experimentally significant effect on the ionic conductivities of the $\mathrm{Li}_{10} \mathrm{Ge}_{1-x} \mathrm{Sn}_{x} \mathrm{P}_{2} \mathrm{~S}_{12}$ series. 
a)

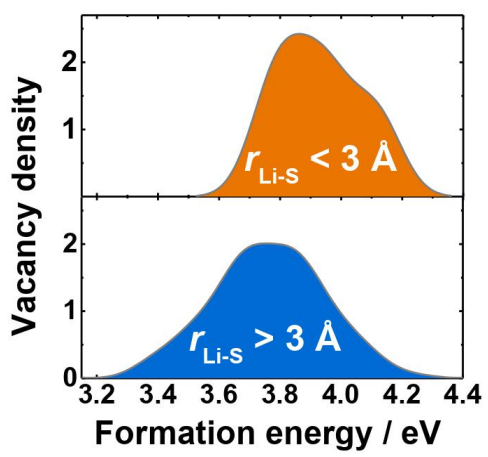

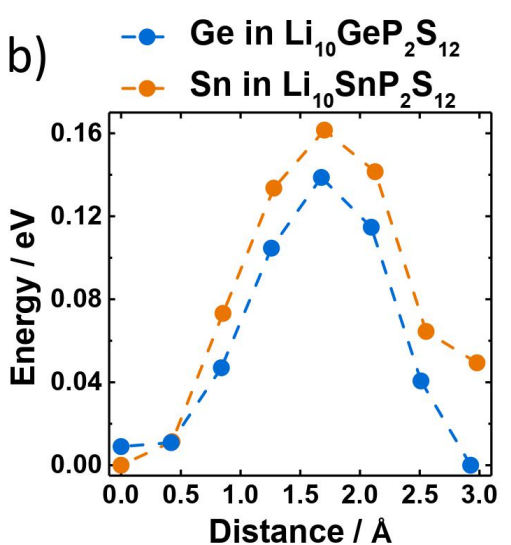

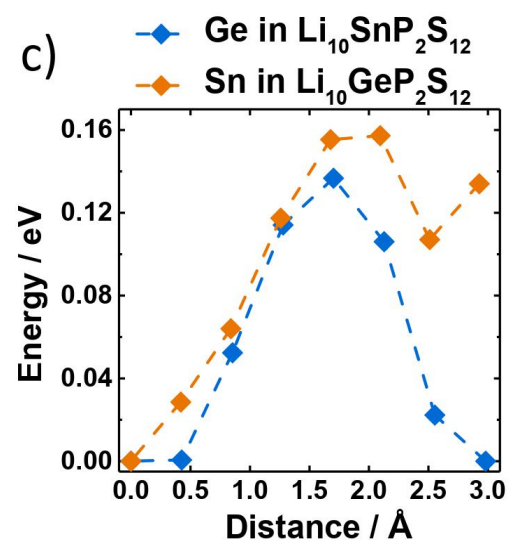

Figure 6: (a) Computed probability distribution of Li vacancy formation energies in a $\mathrm{Li}_{10} \mathrm{GeP}_{2} \mathrm{~S}_{12}$ supercell containing one single Sn ion. The blue distribution shows vacancies far ( $\geq 3 \AA$ ) from the sulfur ions bonded to $S n$, and the orange, those vacancies near the same $S$ ions with a distance $<3 \AA$. The distribution suggests that $\mathrm{Li}^{+}$is more strongly bound to $\mathrm{SnS}_{4}^{4-}$ tetrahedra, compared to $\mathrm{GeS}_{4}{ }^{4-}$. This evidence is confirmed by nudged elastic band calculations performed for (b) the $\mathrm{Li}_{10} \mathrm{GeP}_{2} \mathrm{~S}_{12}$ and $\mathrm{Li}_{10} \mathrm{Sn} \mathrm{P}_{2} \mathrm{~S}_{12}$ structures first, as well as in (c) the respective structure after switching of Ge with Sn and vice versa. Consistently higher activation barriers are found for Sn, irrespective of the starting structure, showing an influence of the charge density itself.

Structure-transport correlations. While the NEB analysis above indicates that the electronic effects of $\mathrm{Ge} \rightarrow$ Sn substitution can produce a meaningful change in the lithium-ion potential energy surface even in the absence of competing geometric effects, this does not mean that geometric effects play no role in the observed conductivity trend in $\mathrm{Li}_{10} \mathrm{Ge}_{1-x} \mathrm{Sn}_{x} \mathrm{P}_{2} \mathrm{~S}_{12}$; ; nor that there is not a geometric component to the solid-electrolyte inductive effect. $\mathrm{Ge} \rightarrow \mathrm{Sn}$ substitution causes the weighted force-constants of the $\mathrm{MS}_{4}{ }^{4-}$ polyhedra to decrease, which is correlated with decreased $\mathrm{S}(2)-\mathrm{Li}(3)$ distances and increased $\mathrm{Li}(3)$ occupancies (Figure 7a). As discussed above, we attribute this response of the lithium substructure to the greater electron density on Sn-bonded S(2) atoms compared to Ge-bonded S(2) atoms, which is a consequence of the weaker $\mathrm{Sn}-\mathrm{S}(2)$ bonding versus $\mathrm{Ge}-\mathrm{S}(2)$ bonding. We also note a strong correlation between the $\mathrm{S}(2)-\operatorname{Li}(3)$ distance and experimentally reported activation energies for lithium conduction (Figure 7b); with increasing Sn content and decreasing $\mathrm{S}(2)-\mathrm{Li}(3)$ distances the ionic-conductivity activation energy increases significantly, which we attribute to the increased strength of the $\mathrm{S}(2) \cdots \mathrm{Li}(3)$ interaction in Sn-substituted $\mathrm{Li}_{10} \mathrm{Ge}_{1-x} \mathrm{Sn}_{x} \mathrm{P}_{2} \mathrm{~S}_{12}$. 

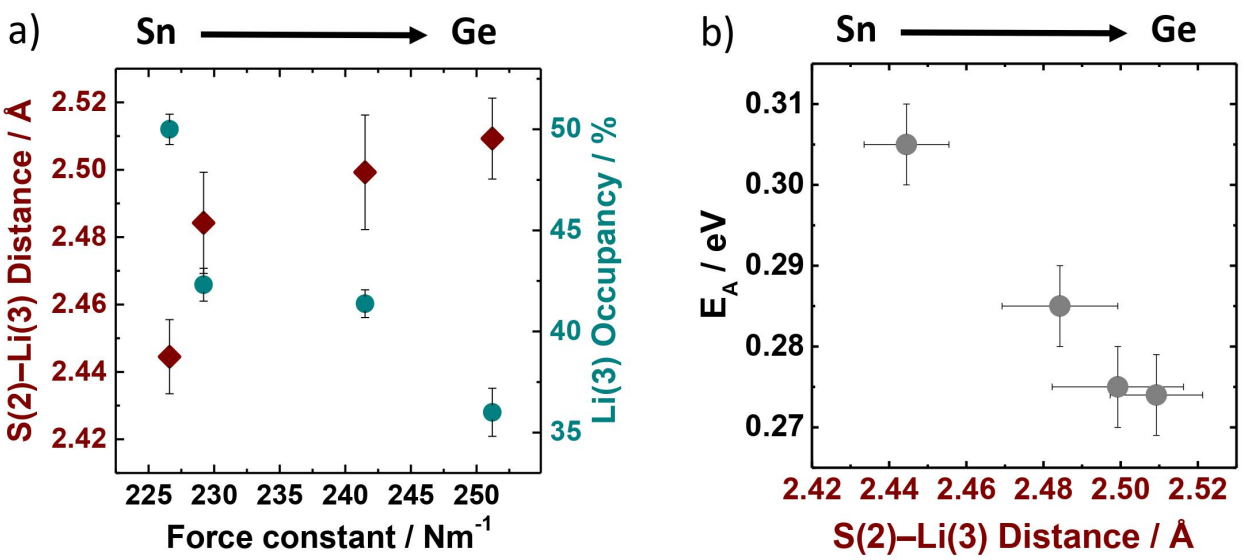

Figure 7: (a) Changes in the S(2)-Li(3) distances and Li(3) occupancies with changing weighted force constant in $\mathrm{Li}_{10} G e_{1-x} \mathrm{Sn}_{x} P_{2} \mathrm{~S}_{12}$. (b) S(2)-Li(3) distance versus previously reported Li-ion conductivity activation energies. Activation energies digitized from reference 35 .

\section{Summary and Conclusion}

The solid-electrolyte inductive effect model offers a possible explanation for the otherwise anomalous conductivity trend observed for $\mathrm{Li}_{10} \mathrm{Ge}_{1-x} \mathrm{Sn}_{x} \mathrm{P}_{2} \mathrm{~S}_{12}$, as well as for a number of other solid electrolyte families. ${ }^{37-40}$ This model proposes that in $\mathrm{Li}_{10} \mathrm{Ge}_{1-x} \mathrm{Sn}_{x} \mathrm{P}_{2} \mathrm{~S}_{12}$ the lower electronegativity of $\mathrm{Sn}$ compared to Ge causes $\mathrm{Sn}-\mathrm{S}$ bonds to be weaker and more polar than analogous Ge-S bonds. The increased polarity of these $\mathrm{Sn}-\mathrm{S}$ bonds corresponds to a larger (more negative) charge density associated with the $\mathrm{Sn}$-bonded S atoms, which in turn causes a stronger Coulombic attraction between these $\mathrm{S}$ atoms and nearby $\mathrm{Li}^{+}$cations. Li-ions adjacent to Sn-bonded S atoms are therefore expected to be more "tightly bound"-i.e. they have lower potential energies - relative to Li-ions further away, than otherwise equivalent $\mathrm{Li}$-ions adjacent to Ge-bonded S atoms. This change in S $\cdots \mathrm{Li}$ interaction-strength is then predicted to change the profile of the potential energy surface for lithium diffusion along the $c$-oriented onedimensional channels, giving a higher barrier to diffusion in $\mathrm{Li}_{10} \mathrm{SnP}_{2} \mathrm{~S}_{12}$ than in $\mathrm{Li}_{10} \mathrm{GeP}_{2} \mathrm{~S}_{12}$, thereby explaining the reduced room-temperature ionic conductivity and higher lithiumconduction activation energy observed in experiments..$^{37-40}$

While this solid-electrolyte inductive effect model is chemically intuitive, and potentially explains a number of otherwise anomalous conductivity trends, there has previously been insufficient data to confirm whether this mechanism does indeed produce a significant effect in lithium-ion solid electrolytes, including $\mathrm{Li}_{10} \mathrm{Ge}_{1-x} \mathrm{Sn}_{x} \mathrm{P}_{2} \mathrm{~S}_{12}$. To address this issue, we have 
conducted a combined high-resolution temperature-dependent neutron-diffraction, Raman spectroscopy, and DFT study of the variation in lithium substructure, bonding interaction, and lithium-ion potential-energy profile in the $\mathrm{Li}_{10} \mathrm{Ge}_{1-x} \mathrm{Sn}_{x} \mathrm{P}_{2} \mathrm{~S}_{12}$ series. Our combined experimental and computational results provide direct evidence for a solid-electrolyte inductive effect in this family of superionic solid electrolytes. Our observed variations in $M-\mathrm{S}$ distances, forceconstants from Raman data, Debye frequencies, and DFT data show that substituting Sn into $\mathrm{Li}_{10} \mathrm{Ge}_{1-x} \mathrm{Sn}_{x} \mathrm{P}_{2} \mathrm{~S}_{12}$ does indeed produce a decrease in $M-\mathrm{S}$ bonding strength, leading to an increasing electron density on S. Further analysis of S-Li distances and Li-site-occupancies alongside DFT-calculated binding energies corroborates a stronger Coulombic attraction between $\mathrm{Li}^{+}$and $\mathrm{S}^{2-}$. Additional c-NEB DFT calculations indicate that these changes in $\mathrm{M}-\mathrm{S}$ and $\mathrm{S} \cdots \mathrm{Li}$ interactions are associated with an increased potential energy barrier for Li diffusing along the $c$-oriented diffusion channels. These data are all consistent with the predictions of the solid-electrolyte inductive effect model, ${ }^{35}$ and provide strong supporting evidence for the existence of this inductive effect in the $\mathrm{Li}_{10} \mathrm{Ge}_{1-x} \mathrm{Sn}_{x} \mathrm{P}_{2} \mathrm{~S}_{12}$ family of superionic solid electrolytes. Finally, analysis of the potential energy profile along the $c$-oriented diffusion channels for $\mathrm{Li}_{10} \mathrm{SnP}_{2} \mathrm{~S}_{12}$ fixed at $\mathrm{Li}_{10} \mathrm{GeP}_{2} \mathrm{~S}_{12}$ geometries and for $\mathrm{Li}_{10} \mathrm{GeP}_{2} \mathrm{~S}_{12}$ fixed at $\mathrm{Li}_{10} \mathrm{SnP}_{2} \mathrm{~S}_{12}$ geometries shows that the predictions of the solid-electrolyte inductive effect model hold even in the absence of the structural changes that accompany Sn-substitution in real materials, suggesting that the inductive effect produces a sufficiently large perturbation to the lithium-ion potential energy profile to be experimentally meaningful, even when decoupled from structural changes to the host-framework.

While the data presented here provide evidence for an experimentally significant solidelectrolyte inductive effect in the $\mathrm{Li}_{10} \mathrm{Ge}_{1-x} \mathrm{Sn}_{x} \mathrm{P}_{2} \mathrm{~S}_{12}$ system, it is unknown to what extent analogous inductive effects may be a factor in the relative ionic conductivities of other families of solid electrolytes. ${ }^{37-40}$ The $\mathrm{Li}_{10} \mathrm{Ge}_{1-x} \mathrm{Sn}_{x} \mathrm{P}_{2} \mathrm{~S}_{12}$ system may be an exceptional case because of the particular geometry of the host-framework - in this crystal structure the $M$-bonded S anions, i.e. those directly affected by $\mathrm{Ge} \rightarrow \mathrm{Sn}$ substitution, are arranged along the sides of the main coriented conduction pathways, and may therefore exhibit a particularly strong influence on Liion diffusion. To what extent the inductive effect does, or does not, play a role in controlling ionic transport in other families of solid electrolytes therefore remains an intriguing question for future study. 


\section{Supporting Information}

Representative Rietveld refinements against time-of-flight neutron diffraction data and the used constrains. Additionally, the crystallographic information format (CIF) files and all structural data as obtained from the refinements for all explored temperatures and compositions are provided. The associated content also contains all the experimental Raman spectra and the shifts relative to the vibration modes.

\section{AUTHOR INFORMATION}

\section{Corresponding Authors}

*wzeier@uni-muenster.de; b.j.morgan@bath.ac.uk

\section{Notes}

The authors declare no competing financial interests.

\section{Acknowledgements}

The experimental research was supported by the Deutsche Forschungsgemeinschaft (DFG) under grant number ZE 1010/4-1. A.G.S. acknowledges EPSRC for PhD funding, B. J. M. acknowledges support from the Royal Society (grant nos. UF130329 \& URF $\backslash R \backslash 191006$ ). The theoretical work was supported by funding from the Faraday Institution (faraday.ac.uk) (EP/S003053/1), grant no. FIRG003. Calculations were performed using the Balena High Performance Computing Service at the University of Bath, the Isambard UK National Tier-2 HPC Service (http://gw4.ac.uk/isambard/) operated by GW4 and the UK Met Office, and funded by EPSRC (EP/P020224/1) and the ARCHER supercomputer, through membership of the UK's HPC Materials Chemistry Consortium, funded by EPSRC grants EP/L000202 and EP/R029431. This research used resources at the Spallation Neutron Source, as appropriate, a DOE Office of Science User Facility operated by the Oak Ridge National Laboratory. S. C. gratefully acknowledges the Alexander von Humboldt Foundation for financial support through a Postdoctoral Fellowship. The authors thank Ashfia Huq (Oak Ridge National Laboratory) for the support during the acquisition of the neutron diffraction data. 


\section{References}

(1) Janek, J.; Zeier, W. G. A Solid Future for Battery Development. Nat. Energy 2016, 1, 16141.

(2) Zhang, Z.; Shao, Y.; Lotsch, B.; Hu, Y.; Hu, L.; Janek, J.; Nazar, L. F.; Nan, C.; Maier, J.; Armand, M.; Chen, L. New Horizons for Inorganic Solid State Ion Conductors. Energy Environ. Sci. 2018, 11, 1945-1976.

(3) Culver, S. P.; Koerver, R.; Krauskopf, T.; Zeier, W. G. Designing Ionic Conductors: The Interplay between Structural Phenomena and Interfaces in Thiophosphate-Based SolidState Batteries. Chem. Mater. 2018, 30, 4179-4192.

(4) Kraft, M. A.; Culver, S. P.; Calderon, M.; Böcher, F.; Krauskopf, T.; Senyshyn, A.; Dietrich, C.; Zevalkink, A.; Janek, J.; Zeier, W. G. Influence of Lattice Polarizability on the Ionic Conductivity in the Lithium Superionic Argyrodites $\mathrm{Li}_{6} \mathrm{PS}_{5} \mathrm{X}(\mathrm{X}=\mathrm{Cl}, \mathrm{Br}, \mathrm{I}) . J$. Am. Chem. Soc. 2017, 139, 10909-10918.

(5) Kong, S.T. Synthesis, Characterization and Structural Chemistry of Lithium Argyrodites, University of Siegen, 2010.

(6) Deiseroth, H. J.; Maier, J.; Weichert, K.; Nickel, V.; Kong, S.T.; Reiner, C. Li7 PS 6 and $\mathrm{Li}_{6} \mathrm{PS}_{5} \mathrm{X}(\mathrm{X}: \mathrm{Cl}, \mathrm{Br}, \mathrm{I})$ : Possible Three-Dimensional Diffusion Pathways for Lithium Ions and Temperature Dependence of the Ionic Conductivity by Impedance Measurements. Z. Anorg. Allg. Chem. 2011, 637, 1287-1294.

(7) Mobility, L.; Deiseroth, H. J.; Kong, S.; Eckert, H.; Vannahme, J.; Reiner, C.; Zaiß, T.; Schlosser, M. $\mathrm{Li}_{6} \mathrm{PS}_{5} \mathrm{X}$ : A Class of Crystalline Li-Rich Solids With an Unusually High $\mathrm{Li}^{+}$Mobility. Angew. Chem. 2008, 120, 767-770.

(8) Bernges, T.; Culver, S. P.; Minafra, N.; Koerver, R.; Zeier, W. G. Competing Structural Influences in the Li Superionic Conducting Argyrodites $\mathrm{Li}_{6} \mathrm{PS}_{5-\mathrm{x}} \mathrm{Se}_{\mathrm{x}} \mathrm{Br}(0 \leq \mathrm{x} \leq 1)$ upon Se Substitution. Inorg. Chem. 2018, 57, 13920-13928.

(9) Minafra, N.; Culver, S. P.; Krauskopf, T.; Senyshyn, A.; Zeier, W. G. Effect of Si Substitution on the Structural and Transport Properties of Superionic Li-Argyrodites. $J$. Mater. Chem. A 2018, 6, 49-52.

(10) Minafra, N.; Kraft, M. A.; Bernges, T.; Li, C.; Schlem, R.; Morgan, B. J.; Zeier, W. G. Local Charge Inhomogeneity and Lithium Distribution in the Superionic Argyrodites $\mathrm{Li}_{6} \mathrm{PS}_{5} \mathrm{X}(\mathrm{X}=\mathrm{Cl}, \mathrm{Br}, \mathrm{I})$. Inorg. Chem. 2020, 59, 11009-11019.

(11) Zhou, L.; Assoud, A.; Zhang, Q.; Wu, X.; Nazar, L. F. A New Family of Argyrodite 
Thioantimonate Lithium Superionic Conductors. J. Am. Ceram. Soc. 2019, 141, 1900219013.

(12) Kraft, M. A.; Ohno, S.; Zinkevich, T.; Koerver, R.; Culver, S. P.; Fuchs, T.; Senyshyn, A.; Indris, S.; Morgan, B. J.; Zeier, W. G. Inducing High Ionic Conductivity in the Lithium Superionic Argyrodites $\mathrm{Li}_{6+} \mathrm{P}_{1-\mathrm{x}} \mathrm{Ge}_{\mathrm{x}} \mathrm{S}_{5} \mathrm{I}$ for All-Solid-State Batteries. J. Am. Chem. Soc. 2018, 140, 16330-16339.

(13) Morgan, B. J. Mechanistic Origin of Superionic Lithium Diffusion in Anion-Disordered $\mathrm{Li}_{6} \mathrm{PS}_{5} \mathrm{X}$ Argyrodites. ChemRxiv 2020, Preprint. DOI: 10.26434/chemrxiv.12349703.v1.

(14) Minafra, N.; Culver, S. P.; Li, C.; Senyshyn, A.; Zeier, W. G. Influence of the Lithium Substructure on the Diffusion Pathways and Transport Properties of the Thio-LISICON $\mathrm{Li}_{4} \mathrm{Ge}_{1-\mathrm{x}} \mathrm{Sn}_{\mathrm{x}} \mathrm{S}_{4}$. Chem. Mater. 2019, 31, 3794-3802.

(15) Kanno, R.; Murayama, M. Lithium Ionic Conductor Thio-LISICON: The $\mathrm{Li}_{2} \mathrm{~S}-\mathrm{GeS}_{2}-$ $\mathrm{P}_{2} \mathrm{~S}_{5}$ System. J. Electrochem. Soc. 2001, 148, A742.

(16) Kanno, R.; Hata, T.; Kawamoto, Y.; Irie, M. Synthesis of a New Lithium Ionic Conductor, Thio-LISICON-Lithium Germanium Sulfide System. Solid State Ionics 2000, 130, 97-104.

(17) Zhou, L.; Assoud, A.; Shyamsunder, A.; Huq, A.; Zhang, Q.; Hartmann, P.; Kulisch, J.; Nazar, L. F. An Entropically Stabilized Fast-Ion Conductor: $\mathrm{Li}_{3.25}\left[\mathrm{Si}_{0.25} \mathrm{P}_{0.75}\right] \mathrm{S}_{4}$. Chem. Mater. 2019, 31, 7801-7811.

(18) Leube, B. T.; Inglis, K. K.; Carrington, E. J.; Sharp, P. M.; Shin, J. F.; Neale, A. R.; Manning, T. D.; Pitcher, M. J.; Hardwick, L. J.; Dyer, M. S.; Blanc, F.; Claridge, J. B.; Rosseinsky, M. J. Lithium Transport in $\mathrm{Li}_{4.4} \mathrm{M}_{0.4} \mathrm{M}^{\prime}{ }_{0.6} \mathrm{~S}_{4}\left(\mathrm{M}=\mathrm{Al}^{3+}, \mathrm{Ga}^{3+}\right.$, and $\mathrm{M}^{\prime}=\mathrm{Ge}^{4+}$, $\mathrm{Sn}^{4+}$ ): Combined Crystallographic, Conductivity, Solid State. Chem. Mater. 2018, 30, $7183-7200$.

(19) Kamaya, N.; Homma, K.; Yamakawa, Y.; Hirayama, M.; Kanno, R.; Yonemura, M.; Kamiyama, T.; Kato, Y.; Hama, S.; Kawamoto, K. A Lithium Superionic Conductor. Nat. Mater. 2011, 10, 682-686.

(20) Bron, P.; Johansson, S.; Zick, K.; Schmedt auf der Günne, J.; Günne, D.; Dehnen, S. S.; Roling, B. $\mathrm{Li}_{10} \mathrm{SnP}_{2} \mathrm{~S}_{12}$ - An Affordable Lithium Superionic Conductor. J. Am. Chem. Soc. 2013, 135, 15694-15697.

(21) Ong, S. P.; Mo, Y.; Richards, W. D.; Miara, L.; Lee, H. S.; Ceder, G. Phase Stability, Electrochemical Stability and Ionic Conductivity of the $\mathrm{Li}_{10 \pm 1} \mathrm{MP}_{2} \mathrm{X}_{12}(\mathrm{M}=\mathrm{Ge}, \mathrm{Si}, \mathrm{Sn}$, 
$\mathrm{Al}$ or $\mathrm{P}$, and $\mathrm{X}=\mathrm{O}, \mathrm{S}$ or Se) Family of Superionic Conductors. Energy Environ. Sci. 2013, 6, 148-156.

(22) Hori, S.; Suzuki, K.; Hirayama, M.; Kato, Y.; Saito, T.; Yonemura, M.; Kanno, R. Synthesis, Structure, and Ionic Conductivity of Solid Solution, $\mathrm{Li}_{10+\delta} \mathrm{M}_{1+\delta} \mathrm{P}_{2-\delta} \mathrm{S}_{12}(\mathrm{M}=$ Si, Sn). Faraday Discuss. 2014, 176, 83-94.

(23) Kato, Y.; Saito, R.; Sakano, M.; Mitsui, A.; Hirayama, M.; Kanno, R. Synthesis , Structure and Lithium Ionic Conductivity of Solid Solutions of $\mathrm{Li}_{10}\left(\mathrm{Ge}_{1-\mathrm{x}} \mathrm{M}_{\mathrm{x}}\right) \mathrm{P}_{2} \mathrm{~S}_{12}(\mathrm{M}=$ Si, Sn). J. Power Sources 2014, 271, 60-64.

(24) Bron, P.; Dehnen, S.; Roling, B. $\mathrm{Li}_{10} \mathrm{Si}_{0.3} \mathrm{Sn}_{0.7} \mathrm{P}_{2} \mathrm{~S}_{12}$ - A Low-Cost and Low-GrainBoundary-Resistance Lithium Superionic Conductor. J. Power Sources 2016, 329, 530535.

(25) Kato, Y.; Hori, S.; Saito, T.; Suzuki, K.; Hirayama, M.; Mitsui, A.; Yonemura, M.; Iba, H.; Kanno, R. High-Power All-Solid-State Batteries Using Sulfide Superionic Conductors. Nat. Energy 2016, 1, 16030.

(26) Ohno, S.; Banik, A.; Dewald, G. F.; Kraft, M. A.; Krauskopf, T.; Minafra, N.; Till, P.; Weiss, M.; Zeier, W. G. Materials Design of Ionic Conductors for Solid State Batteries. Prog. Energy 2020, 2, 022001.

(27) Muy, S.; Voss, J.; Schlem, R.; Koerver, R.; Sedlmaier, S. J.; Maglia, F.; Lamp, P.; Wolfgang, G.; Shao-Horn, Y. High-Throughput Screening of Solid-State Li-Ion Conductors Using Lattice-Dynamics Descriptors. IScience 2019, 16, 270-282.

(28) Katcho, N. A.; Carrete, J.; Reynaud, M.; Rousse, G.; Casas-Cabanas, M.; Mingo, N.; Rodriguez-Carvajal, J.; Carrasco, J. An Investigation of the Structural Properties of Li and $\mathrm{Na}$ Fast Ion Conductors Using High-Throughput Bond-Valence Calculations and Machine Learning. J Appl. Cryst . 2019, 52, 148-157.

(29) Zhang, Y.; He, X.; Chen, Z.; Bai, Q.; Nolan, A. M.; Roberts, C. A.; Banerjee, D.; Matsunaga, T.; Mo, Y.; Ling, C. Unsupervised Discovery of Solid-State Lithium Ion Conductors. Nat. Commun. 2019, 10, 5260.

(30) Liu, Y.; Wang, S.; Nolan, A. M.; Ling, C.; Mo, Y. Tailoring the Cation Lattice for Chloride Lithium-Ion Conductors. Adv. Energy Mater. 2020, 2002356.

(31) Iwasaki, R.; Hori, S.; Kanno, R.; Yajima, T.; Hirai, D.; Kato, Y.; Hiroi, Z. Weak Anisotropic Lithium-Ion Conductivity in Single Crystals of $\mathrm{Li}_{10} \mathrm{GeP}_{2} \mathrm{~S}_{12}$. Chem. Mater. 2019, 31, 3694-3699. 
(32) Weber, D. A.; Senyshyn, A.; Weldert, K. S.; Wenzel, S.; Zhang, W.; Kaiser, R.; Berendts, S.; Janek, J.; Zeier, W. G. Structural Insights and 3D Diffusion Pathways within the Lithium Superionic Conductor $\mathrm{Li}_{10} \mathrm{GeP}_{2} \mathrm{~S}_{12}$. Chem. Mater. 2016, 28, 59055915.

(33) Inagaki, M.; Suzuki, K.; Hori, S.; Yoshino, K.; Matsui, N.; Yonemura, M.; Hirayama, M.; Kanno, R. Conduction Mechanism of $\mathrm{Li}_{10} \mathrm{GeP}_{2} \mathrm{~S}_{12}$ - Type Lithium Superionic Conductors in a Li-Sn-Si-P-S System. Chem. Mater. 2019, 31, 3485-3490.

(34) Kahle, L.; Marcolongo, A.; Marzari, N. Modeling Lithium-Ion Solid-State Electrolytes with a Pinball Model. Phys. Rev. Mater. 2018, 2, 065405.

(35) Krauskopf, T.; Culver, S. P.; Zeier, W. G. Bottleneck of Diffusion and Inductive Effects in $\mathrm{Li}_{10} \mathrm{Ge}_{1-\mathrm{x}} \mathrm{Sn}_{\mathrm{x}} \mathrm{P}_{2} \mathrm{~S}_{12}$. Chem. Mater. 2018, 30, 1791-1798.

(36) Wang, Y.; Richards, W. D.; Ong, S. P.; Miara, L. J.; Kim, J. C.; Mo, Y.; Ceder, G. Design Principles for Solid-State Superionic Conductors. Nat. Mater. 2015, 14, 1026.

(37) Strangmüller, S.; Eickhoff, H.; Raudaschl-sieber, G.; Kirchhain, H.; Sedlmeier, C.; Wüllen, L. Van; Gasteiger, H. A.; Fässler, T. F.; Wüllen, L. Van; Gasteiger, H. A.; et al. Modifying the Properties of Fast Lithium Ion Conductors - The Lithium Phosphidotetrelates $\mathrm{Li}_{14} \mathrm{SiP}_{6}, \mathrm{Li}_{14} \mathrm{GeP}_{6}$ and $\mathrm{Li}_{14} \mathrm{SnP}_{6}$. Chem. Mater. 2020, 32, 69256934.

(38) Zhang, Z.; Ramos, E.; Lalere, F.; Assoud, A.; Kaup, K.; Hartmann, P.; Nazar, L. $\mathrm{Na}_{11} \mathrm{Sn}_{2} \mathrm{PS}_{12}$ : A New Solid State Sodium Superionic Conductor. Energy Environ. Sci. 2017, 11, 87-93.

(39) Yu, Z.; Shang, S. L.; Seo, J. H.; Wang, D.; Luo, X.; Huang, Q.; Chen, S.; Lu, J.; Li, X.; Liu, Z. K.; Wang, D. Exceptionally High Ionic Conductivity in $\mathrm{Na}_{3} \mathrm{P}_{0.62} \mathrm{As}_{0.38} \mathrm{~S}_{4}$ with Improved Moisture Stability for Solid-State Sodium-Ion Batteries. Adv. Mater. 2017, 29 , 1605561.

(40) Pareek, T.; Dwivedi, S.; Singh, B.; Kumar, D.; Kumar, P.; Kumar, S. LiSnZr( $\left(\mathrm{PO}_{4}\right)_{3}$ : NASICON-Type Solid Electrolyte with Excellent Room Temperature $\mathrm{Li}^{+}$Conductivity. J. Alloys Compd. 2019, 602-611.

(41) Huq, A.; Kirkham, M.; Peterson, P. F.; Hodges, J. P.; Whitfield, P. S.; Page, K.; Hugle, T.; Iverson, E. B.; Parizzia, A.; Rennichb, G. POWGEN: Rebuild of a Third-Generation Powder Diffractometer at the Spallation Neutron Source. J. Appl. Crystallogr. 2019, 52, 1189-1201. 
(42) Coelho, A. A. TOPAS-Academic. Brisbane, Australia, 2007.

(43) Momma, K.; Izumi, F. VESTA 3 for Three-Dimensional Visualization of Crystal, Volumetric and Morphology Data. J. Appl. Crystallogr. 2011, 44, 1272-1276.

(44) Physik, T.; Wien, T. U.; Hauptstrasse, W. Ab Initio Molecular Dynamics for Liquid Metals. Phys. Rev. B 1993, 47, 558-561.

(45) Kresse, G.; Furthmu, J. Efficiency of Ab-Initio Total Energy Calculations for Metals and Semiconductors Using a Plane-Wave Basis Set. Comput. Mater. Sci. 1996, 6, 15-50.

(46) Kresse, G.; Furthmu, J. Efficient Iterative Schemes for Ab Initio Total-Energy Calculations Using a Plane-Wave Basis Set. Phys. Rev. B 1996, 54, 11169-11186

(47) Blöochl, P. E. Projector Augmented-Wave Method. Phys. Rev. B 1994, 50, 1795317979.

(48) Csonka, I.; Vydrov, O. A.; Scuseria, G. E.; Constantin, L. A.; Perdew, J. P.; Ruzsinszky, A.; Zhou, X.; Burke, K. Restoring the Density-Gradient Expansion for Exchange in Solids and Surfaces. Phys. Rev. Lett. 2008, 100, 36406.

(49) Manz, T. A. Introducing DDEC6 Atomic Population Analysis : Part 3. Comprehensive Method to Compute Bond Orders. RSC Adv 2017, 7, 45552-45581.

(50) Deringer, V. L.; Tchougr, A. L.; Dronskowski, R. Crystal Orbital Hamilton Population (COHP) Analysis As Projected from Plane-Wave Basis Sets. J. Phys. Chem. A 2011, $115,5461-5466$.

(51) Maintz, S.; Deringer, V. L.; Tchougr, A. L. Analytic Projection From Plane-Wave and PAW Wavefunctions and Application to Chemical-Bonding Analysis in Solids. $J$. Comput. Chem. 2013, 34, 2557-2567.

(52) Maintz, S.; Deringer, V. L.; Tchougr, A. L.; Dronskowski, R. LOBSTER : A Tool to Extract Chemical Bonding from Plane-Wave Based DFT. J. Comput. Chem. 2016, 37, 1030-1035.

(53) Henkelman, G.; Uberuaga, B. P.; Jonsson, H. A Climbing Image Nudged Elastic Band Method for Finding Saddle Points and Minimum Energy Paths and Minimum Energy Paths. J. Chem. Phys. 2000, 113, 9901-9904.

(54) Rong, Z.; Kitchaev, D.; Canepa, P.; Huang, W.; Ceder, G. An Efficient Algorithm for Finding the Minimum Energy Path for Cation Migration in Ionic Materials. J. Chem. Phys. 2016, 145, 074112. 
(55) Lany, S.; Zunger, A. Accurate Prediction of Defect Properties in Density Functional Supercell Calculations. Model. Simul. Mater. Sci. Eng. 2009, 17, 084002.

(56) Makov, G.; Payne, M. C. Periodic Boundary Conditions in Ab Initio Calculations. Phys. Rev. B 1995, 51, 4014-4022.

(57) Persson, K. Materials Data on $\mathrm{Li}_{10} \mathrm{Ge}\left(\mathrm{PS}_{6}\right)_{2}$ (SG:1) by Materials Project. United States N.p. 2016.

(58) Ping, S.; Davidson, W.; Jain, A.; Hautier, G.; Kocher, M.; Cholia, S.; Gunter, D.; Chevrier, V. L.; Persson, K. A.; Ceder, G. Python Materials Genomics (Pymatgen): A Robust, Open-Source Python Library for Materials Analysis. Comput. Mater. Sci. 2013, $68,314-319$.

(59) Squires, A. G.; Morgan, B. J. Dataset for Evidence for the Existence of an Inductive Effect in Superionic Conductors. Bath Univ. Bath Res. Data Arch. Press.

(60) Walt, S. Van Der; Colbert, S. C.; Varoquaux, G. The NumPy Array: A Structure for Efficient Numerical Computation. Comput. Sci. Eng. 2011, 13, 22-30.

(61) Mckinney, W. Data Structures for Statistical Computing in Python. Proc. 9th Python Sci. Conf. 2010, 51-56.

(62) Hunter, J. D. Matplotlib: A 2D Graphics Environment. Comput. Sci. Eng. 2007, 9, 9095.

(63) Shannon, R. D. Revised Effective Ionic Radii and Systematic Studies of Interatomie Distances in Halides and Chaleogenides. Acta Crystallogr. Sect. A 1976, A32, 751.

(64) Lucovsky, G.; Deneufville, J. P.; Galeener, F. L. Study of the Optic Modes of $\mathrm{Ge}_{0.30} \mathrm{~S}_{0.70}$ Glass by Infrared and Raman Spectroscopy. Phys. Rev. B 1974, 9, 1591-1597.

(65) Xu, M.; Ding, J.; Ma, E. One-Dimensional Stringlike Cooperative Migration of Lithium Ions in an Ultrafast Ionic Conductor. Appl. Phys. Lett. 2012, 101, 031901.

(66) Allred, A. L.; Rochow, E. G. A Scale of Electronegativity Based. 1958, 5, 1954-1956.

(67) Rahm, M.; Zeng, T.; Hoffmann, R. Electronegativity Seen as the Ground-State Average Valence Electron Binding Energy. J. Am. Chem. Soc. 2019, 141, 342-351.

(68) Etourneau, J.; Portier, J.; Ménil, F. The Role of the Inductive Effect in Solid State Chemistry: How the Chemist Can Use It to Modify Both the Structural and the Physical Properties of the Materials. J. Alloys Compd. 1992, 188, 1-7.

(69) Kuznetsov, D. A.; Han, B.; Yu, Y.; Rao, R. R.; Hwang, J.; Roman-Leshkov, Y.; Shao- 
Horn, Y. Tuning Redox Transitions via Inductive Effect in Metal Oxides and Complexes, and Implications in Oxygen Electrocatalysis. Joule 2018, 2, 225-244.

\section{Table of contents image}

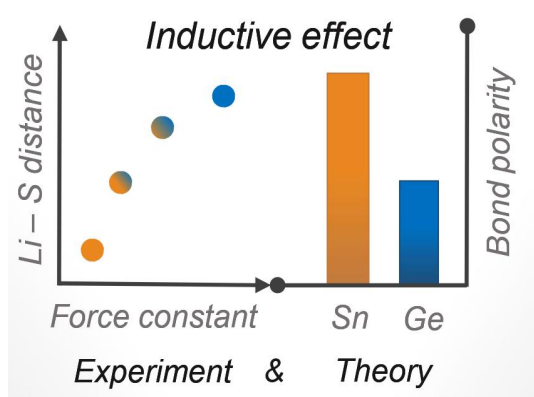

